\title{
HOW THE CONTENTS OF A BACHELOR'S DEGREE FINAL PROJECT OF ENGINEERING EVOLVE TOWARDS INNOVATIVE SCIENTIFIC KNOWLEDGE: KEYS TO SUCCESS
}

\author{
Cristina Núñez $\mathbb{D}^{D}$, Ana Guinea ${ }^{\mathbb{D}}$, Sara Callau ${ }^{\mathbb{D}}$, Christophe Bengoa ${ }^{\mathbb{D}}$, \\ Josep Basco $\mathbb{D}$, Jordi Gavaldà \\ Chemical Engineering Department, Universitat Rovira i Virgili (Spain) \\ cristina.nunez@estudiants.urv.cat, ana.guinea@estudiants.urv.cat, sara.callau@estudiants.urv.cat, \\ christophe.bengoa@urv.cat, jose.basco@urv.cat, jordi.gavalda@urv.cat
}

\section{Abstract}

The Bachelor's Degree Final Project (BDFP) of our school aims to develop a real constructive project, enhance cooperative teamwork and increase productivity of students.

We present a real case study, related with engineering and scientific innovation results obtained by BDFP, which has led to an innovative scientific study presented at the 7th European Meeting on Chemical Industry and Environment and published in EMChIE 2015 Conference Proceedings.

The objectives of this paper are:

- Describing the design and implementation of a BDFP of engineering that encompasses the development of the characteristic elements of engineering and constructive work and, at the same time, it is scientifically innovative.

- Showing the methodology used for its development.

- Presenting the results obtained.

- Emphasizing the importance of teachers, teamwork of students and the use of real case studies in the conceptual development of a BDFP.

- Enhancing the possibility that the BDFP of Engineering can solve real engineering problems and to be precursors of Innovation and Scientific Knowledge developers.

- Learning engineering and, at the same time, providing Science new knowledge and applications.

Keywords - Bachelor's Degree Final Project (BDFP) or Treball Fi de Grau (TFG), Case study, Methodology, Innovative scientific study. 


\section{Introduction}

The academic year 2012-2013 was the last in which in our School, Escola Tècnica Superior d'Enginyeria Quimica of Rovira i Virgili University (hereinafter referred to ETSEQ by the Catalan acronym), as in many other schools of engineering of the Spanish State, the Final Project Degree of the old Chemical Engineering degree (called PFC by the Catalan acronym; Projecte Fi de Carrera) coexisted with the Bachelor's Degree Final Project Degree of the new Chemical Engineering bachelor degree (called TFG by the Catalan acronym; Treball Fi de Grau). Afterward, the TFG consolidated as the official Final Project and, in our case, with fewer academic courses and credits since we change, respectively, 5 to 4 years and 33 to 12 credits.

Although the objectives of the TFG are the same as the ones of its predecessor, the PFC, it consists of real work; to enhance cooperative teamwork supervised by professionals of the engineering and higher education; to increase the productivity of students, and to experiment with the students the dynamics of a real work (Cabello, Montané, Castells \& Gavaldà, 2014).

In many cases, the real work takes place in collaboration with companies and industries in the area (García, Font \& Gavaldà, 2009), which offer external tutors to monitor the development of the TFG's together with the professor of the School.

In this case study, the External Tutor was the director of an assessment entity of chemical and technological risks. He and the Associate Professor of the School (at the same time "senior" engineer in exercise in a multinational company) commissioned the team to design a chlorine storage unit and the implementation of measures to mitigate the risk to this unit.

The result of the project, after more than 750 hours of working by the three students that formed the team, was the TFG named "Chlorine storage unit design and application of risk mitigation measures" (Guinea, Nuñez \& Callau, 2014) in which the students act as a "pseudoprofessional" engineers, achieving the requirements of the "Property" (represented by the Associate Professor and the External Tutor) and the regulations of the School (ETSEQ, 2014 2016).

The results presented in the TFG were related to engineering and were constructive as they corresponded to the design. Besides, it also included another part related to scientific innovation (proposal and application of high-risk mitigation measures in order to minimise the risk associated with plant premises and surrounding population). Both parts of the project were separated and, at the end, it resulted in an innovative scientific study (Guinea et al., 2015a) which 
was presented by the TFG students in an oral session in the International Conference "7th European Meeting on Chemical Industry and Environment". Finally, the study was published in “EMChIE 2015 Conference Proceedings" study (Guinea et al., 2015b).

\section{Approach, methodology and results}

The professor team designed a TFG based on the knowledge and the real experience of the Associate Professor; the applied and specific knowledge of the External Tutor, and the knowledge and teaching methodology of the Professor of the subject. In the initial proposal of the project, it was already included the idea of developing a TFG that was more complex than the habitual.

This TFG was offered to a team of three students, one of them with little experience in the assessment of industrial risks. The team assumed the project as a professional work, taking the initial decision of doing it in English, despite the fact that the native language of the three team members was Catalan or Spanish. They also planned the project in a careful and meticulous way in respect of the activities, timing and individual responsibilities of each member of the team.

The Professor team (Associate, External and the Professor of the subject) provided support and assessment to the team members (in total, approximately 30 hours of joint work). When half of the work was already done, some concepts of innovation were included, as well as the necessity of applying knowledge and scientific methodologies more specific to the study case. The result was the TFG 214102 titled "Chlorine storage unit design and application of risk mitigation measures" (Guinea et al., 2014) with 173 pages and a presentation of 52 slides.

The basic contents were: description of the process, process alternatives, equipment and control system designs, safety and quantitative risk assessment of the process, environmental analysis, equipment maintenance, operations manual, economic study and, finally, a comparative study of the alternatives, taking into account the equilibrium between the population risk acceptance and the economical aspects related to new investments in order to improve the installations. 


\subsection{Description of the TFG}

During the development of the TFG and in the final presentation of the project, it was confirmed the homogeneity of the three members of the team and the good level of the work (the final evaluation of them was an outstanding grade).

Currently, the TFG of Chemical Engineering degree in ETSEQ is evaluated in different stages. First, the Tutors and the Professor of the subject follow up the development of the TFG. In the middle of the project, the students present an individual report about the accomplishment of the programming envisaged and a declaration of the participation of all the members of the team, when the TFG is not individual. The results obtained have no consequences in the final evaluation, as the aim is to correct the situation in case of delay and/or if there is not homogeneity in the participation and elaboration of the TFG by the team members.

The strict evaluation process starts when the TFG proposal is handed in. In this document, the contributions of each member of the team and the group work are distinguished by a colour code. This TFG proposal is evaluated, authorized, presented and individually defended in front of a tribunal, which is made up of a maximum of three TFG Professors and the Tutor. Before the presentation and the defence, each member of the tribunal provides his or her evaluation, which will be the $50 \%$ of the final mark. Another $10 \%$ is provided by the ETSEQ Tutor. The $40 \%$ remaining corresponds to the evaluation of the presentation $(20 \%)$ and the defence $(20$ $\%)$. In Table 1 and 2, it can be observed the competences evaluated in every stage. 
Individual skills

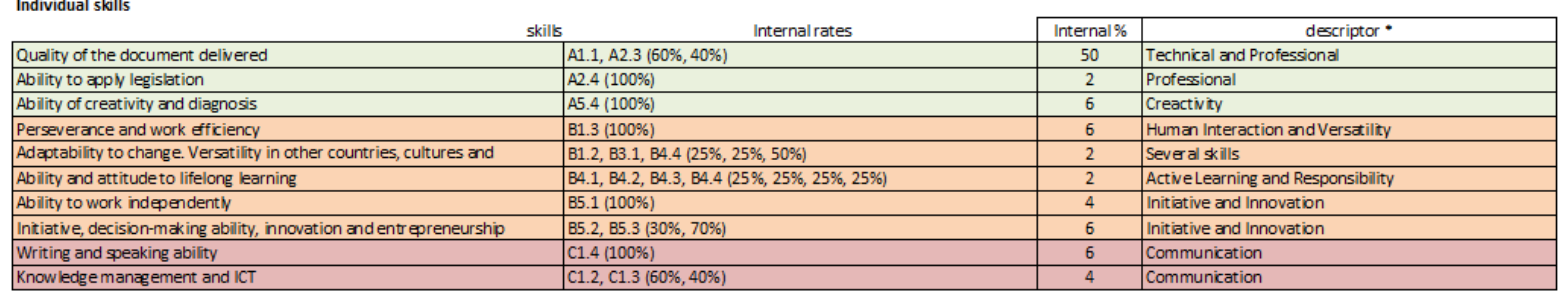

Individual skills in relation to other

\begin{tabular}{|c|c|c|c|}
\hline Ability to work in team & B3.2, B3.3 (50\%, 50\%) & 2 & Teamwork \\
\hline \begin{tabular}{|l} 
Lemdership and Organizaional Capacity \\
\end{tabular} & AA.12, B2.1, B2.2, B2.3, B2.5 (40\%, 15\%, 15\%, 15\%, 15\%) & 4 & Human Interaction, Versatility and Leadership \\
\hline Professionalism and Social Responsibility & $\mathrm{C} 2.1, \mathrm{C} 2.2(50 \%, 50 \%)$ & 2 & Social Skill (nuclear) \\
\hline
\end{tabular}

Tribunal rating (90\%)

Written document (50\%)

\begin{tabular}{|l|l|l|l|}
\cline { 3 - 5 } \multicolumn{2}{l|}{} & Inter nal\% & \multicolumn{1}{c|}{ decriptor * } \\
\hline Quality of the document delivered & $\mathrm{A} 1.1, \mathrm{~A} 2.3(50 \%, 50 \%)$ & 75 & Technical and Professional \\
\hline Writing Ability & $\mathrm{C} 1.4(100 \%)$ & 15 & Communication \\
\hline Knowledge management and ICT & $\mathrm{C} 1.2, \mathrm{C} 1.3(60 \%, 40 \%)$ & 10 & Communication \\
\hline
\end{tabular}

Presentation and defense (40\%)

\begin{tabular}{|l|l|l|l|}
\cline { 3 - 5 } \multicolumn{2}{c|}{} & Inter nal\% & \multicolumn{1}{c|}{ descriptor * } \\
\hline Presentation of TFG & A6.1(100\%) & 40 & Technical and Professional \\
\hline Defense of TFG & $\mathrm{A} 6.1(100 \%)$ & 35 & Technical and Professional \\
\hline Speaking Ability & $\mathrm{C} 1.4(100 \%)$ & 15 & Communication \\
\hline Knowledge management and ICT & $\mathrm{C1.2,C1.3(60 \% ,40 \% )}$ & 10 & Communication \\
\hline
\end{tabular}

In Table 2 it can observed the skils described with AN.N, and BN.N and CN.N extracted from the TFG's Educational Guide 2015 - 2016 of ETSEQ

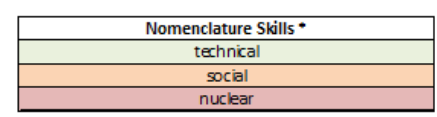

Table 1. Competences evaluated in the TFG of GEQ of ETSEQ and its percent quantification

\begin{tabular}{|c|c|c|}
\hline Type A & Code & Specific Competences \\
\hline & A1.1 & Effectively apply knowledge of basic, scientific and technological subjects of engineering \\
\hline & A 2.3 & $\begin{array}{l}\text { Ability to draft, sign and develop projects in the field of industrial engineering, speciality in } \\
\text { Industrial Chemistry, with the objective of construction, renovation, repair, maintenance, } \\
\text { demolition, manufacture, installation, assembly or use of structures, mechanical equipment, } \\
\text { energy facilities, electrical and electronic installations, installations and industrial plants and } \\
\text { manufacturing processes and automation }\end{array}$ \\
\hline & A2.4 & $\begin{array}{l}\text { Knowledge, understanding and ability to apply the necessary legislation on the exercise of the } \\
\text { profession of Industrial Technical Engineer, speciality in Industrial Chemistry. }\end{array}$ \\
\hline & A4.12 & $\begin{array}{l}\text { Knowledge and skills to organize and manage projects. Know the organizational structure and } \\
\text { functions of a project office }\end{array}$ \\
\hline & A5.4 & Ability to design, manage and operate procedures \\
\hline & A6.1 & $\begin{array}{l}\text { Original exercise that must be performed individually and present and defend in front of a } \\
\text { University tribunal, consisting of a project in the field of the specific technologies of industrial } \\
\text { engineering of professional nature. In this project, the skills acquired in the education must be } \\
\text { synthesized and integrated }\end{array}$ \\
\hline
\end{tabular}




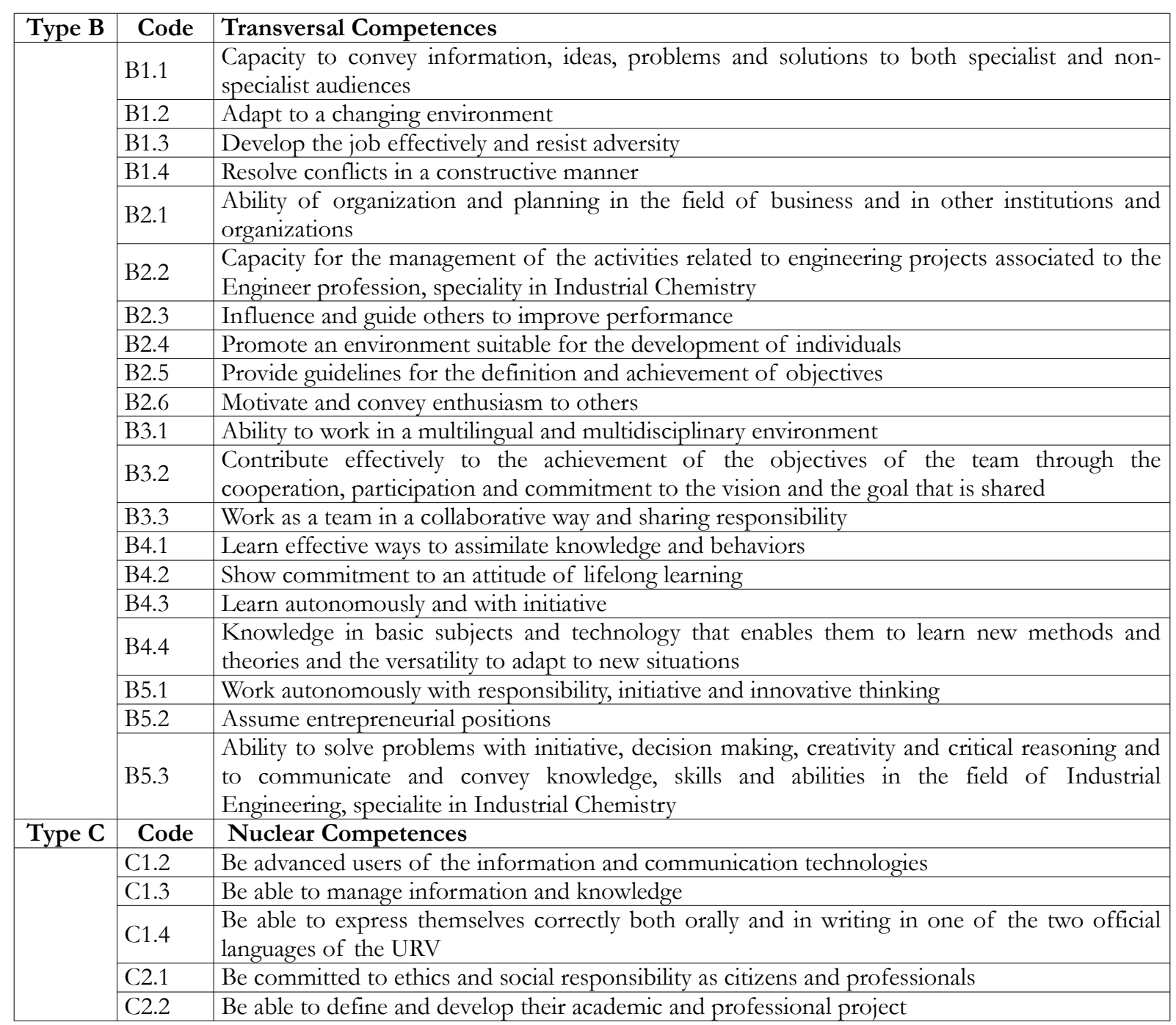

Table 2. List and nomenclature of the competences evaluated in the TFG of GEQ in ETSEQ

After the good results obtained from the TFG, it was offered to the students, who in that moment were already graduate and Engineers, the possibility to take advantage of the results obtained and to try to publish them in a prestigious Scientific Forum. This fact took place when the work "Chlorine storage design based on risk analysis: cost or safety?" was accepted in the 7th European Meeting on Chemical Industry and Environment in 2015 (EMChIE). 


\subsection{Description of the scientific work presented and results}

In Tarragona there is one of the biggest petrochemical complexes of Spain, in which chemical and physical processes that involves big quantities of dangerous substances take place. This fact requires focusing on safety because this complex is surrounded by crowded areas such as cities, villages, historical monuments that take part of the Patrimony of Humanity and some amusement parks. This is why it is necessary to install safety measures to make sure that the consequences on the population are as maximum acceptable as possible, despite the risk that implies this industrial complexes, essentially chemical and petrochemical (Gangopadhyay, Das \& Mukherjee, 2005).

Due to this situation and leveraging the realization of the TFG by a team of Chemical Engineering degree students of ETSEQ, it was decided to carry out, at the same time, a study of quantitative risk assessment of the basic design of the installation and the consequences of the implementation of additional safety measures (Planas, Arnaldos, Darbra, Muñoz, Pastor \& Vilchez, 2014). In order to do so, a chlorine storage installation was selected, as chlorine is one of the most dangerous substances in this petrochemical complex. So, through this academic project, it was possible to extrapolate a general interest real case (Tseng Liu, Chang \& Shu, 2008).

The project started with the design of the chlorine storage tank and the corresponding quantitative risk assessment study. Chlorine is a highly toxic substance and it is considered dangerous substance by Directive 2012/18/UE of the European Parliament and of the Council, 4th July 2012 (Bernechea \& Arnaldos Viger, 2013). The breaking of a reactor, tank, pipeline or pump of the installation would entail a loss containment, which consequences could be very harmful, at first for the company workers and then for the area population, if preventive measures have not been taken (Marco, Peña \& Santamaria, 1998).

For this reason, the technical project consisted of a second part in which a meticulous study of several preventive measures that could be installed in the equipment is done. These technological measures are established to avoid the possible consequences of an accident. Keeping it in mind that the risk always exists, even though it is small, the aim of the Engineer is to design the installation in a way which comprises maximum safety to population (Soman \& Sundararaj, 2015). In order to make the best comparison of these measures, three parameters have been considered: the occurrence probability of a possible accident, the reach of the toxic dispersion as a consequence and the economic investment (Vílchez, Espejo \& Casal, 2011). 
First, three different designs of the storage installation have been considered, changing the number of tanks and their volume, for a certain quantity of chlorine. Once the installation is set, a possible breaking of one of the thanks is studied, as well as the toxic dispersion produced. Finally, the comparative study of different mitigation and preventive measures that can be installed is done. Figure 1 shows the effect of the toxic cloud on population.

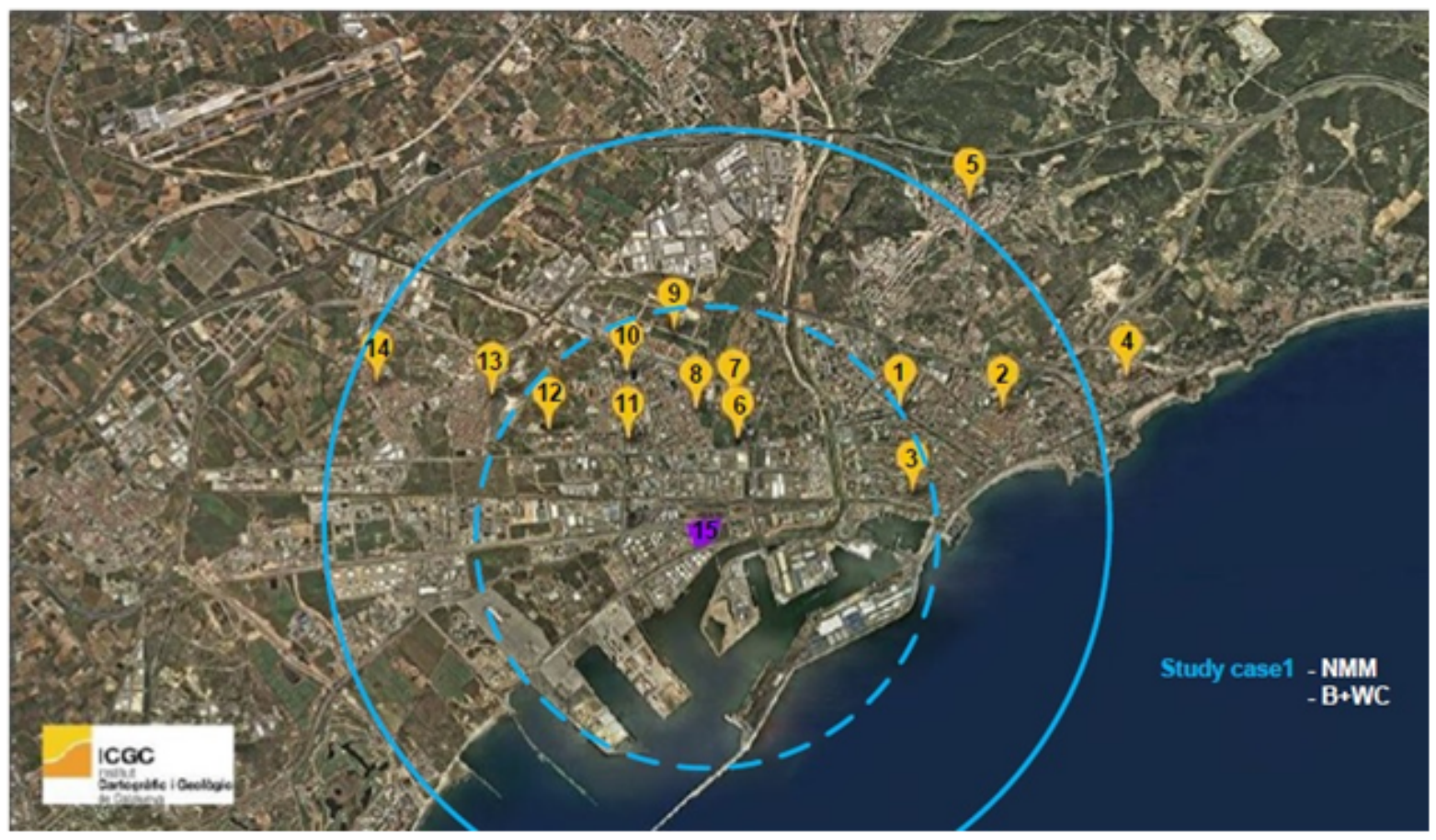

Figure 1. Representation of the distances of affectation of the possible accident according to the designs used (none or bund and water curtains)

The measures proposed are the installation of a bund for liquid leaks (chlorine is stored under pressure in the liquid phase); water curtains to sweep along the gas chlorine, and an absorption column to recover the released gas and to confine it. All these measures are studied separately and also combined with each other. The Figure 2 presents the Iso-risk curves obtained for each case configuration. The higher frequency is $10-8$ oc/year, which means that the risk is acceptable. 


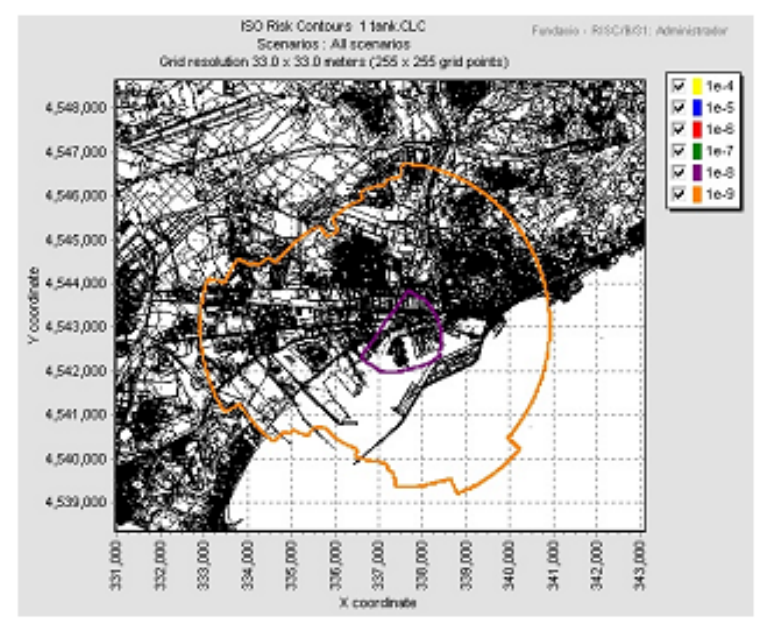

a) 1 tank with no mitigation measures.

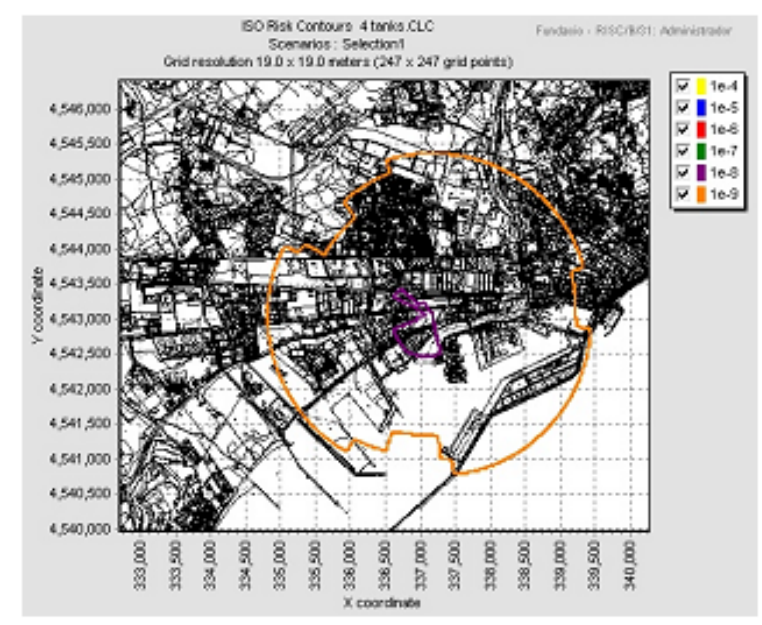

b) 4 tanks with all mitigation measures.

Figure 2. Example of risk curves of a Quantitative Risk Analysis. Each curve represents the affectation areas where the risk is constant

It is calculated the effect of the accident and the consequences on population for each chlorine storage design with the mitigation measures. The results lead to the conclusion which storage design and which safety measures are the optimums. The acceptance criterion of the social risk is presented in Figure 3.

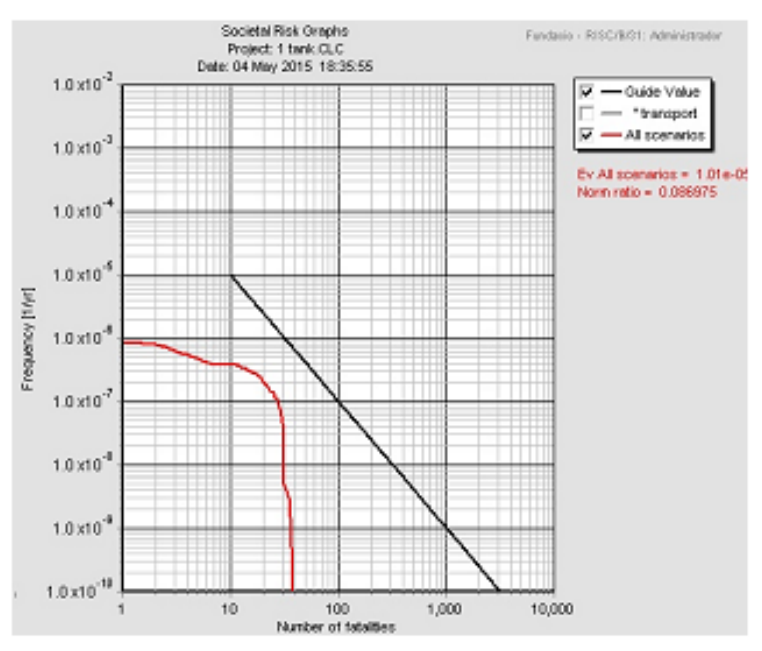

a) 1 tank with no mitigation measures.

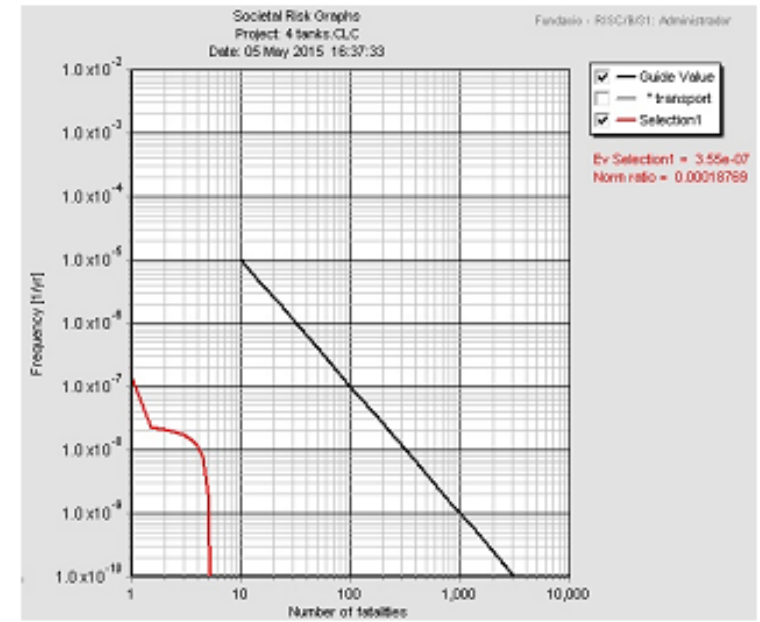

b) 4 tanks with all mitigation measures.

Figure 3. Representation of social risk values. It relates the frequency of occurrence of a possible crash with the mortality associated. If the curve is located below the straight line, the risk is acceptable. Left: no mitigation measures, right: bund and water curtains 
The design that has the smallest effect on population is the one that contains the largest number of tanks, which have the smallest volume, and using all the mitigation and preventive measures. The fact that it has more tanks implies an increase in the probability of occurrence of the possible accident (1 possibility of breaking every 210.000 years). The simple fact of reducing the volume of the tanks reduces the distance from 5.000 meters to 3.700 meters. In addition, the utilization of all mitigation measures reduces this distance to $12 \mathrm{~m}$. This means that the possible accident would only affect the installation. Referring to economics, obviously this design is the most expensive. The implementation of all mitigation measures increases the cost process in $25 \%$, from 4.58 to $5.71 \mathrm{M} €$. This increment allows total reduction of the fatalities outside the limits of the industry.

When deciding which the best design is, it is necessary to pay attention to both safety and investment (Caputo, Pelagaggeb \& Palumbo, 2011). In this point there is always controversy because the best design implies two objectives that are incompatible: maximum safety and minimum investment. It is clear that safety is very expensive and, on the other hand, it is impossible to achieve total safety. The questions that remain are "who is the responsible of taking the final decision, companies or politicians?" and, above all, "how far the limit is acceptable?”

The dynamics, shown in Figure 4, involved the standard development of the TFG and the introduction in it of new aspects of scientific innovation using the best available techniques, which are analytics and numerical simulation, with the aim of obtaining results that reaffirm the hypothesis effect carried out during all the process. Some of the most significant results depicted in Figures 1, 2 and 3 were presented in the article published in EMChIE 2015 Conference Proceedings (Guinea et al., 2015b). 


\section{TFG}

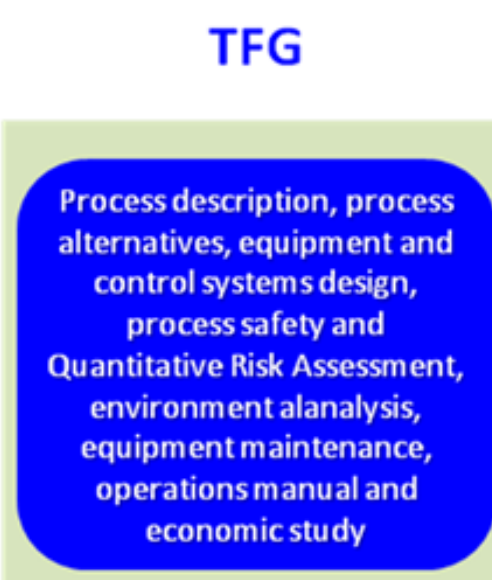

\section{Scientific} innovation

Comparative study of alternatives, taking into account the balance between risk for the population and economic aspects related to new investments to improve industrial facilities

\section{Results}

Chlorine storage design based on risk analysis: cost or safety?

Figure 4. Dynamics and results of the transition between a TFG and a research and scientific innovation work

\section{Conclusions}

The teamwork of the students, the tutoring and supervision of the Professor team (School Tutor, External Tutor and the Professor of the subject) and the duality of objectives of the project, promote very good results, such as a high level of satisfaction, an outstanding qualifications and an initial immersion in scientific research, which also has a positive impact on their curriculum. Results expected to be repeated in the future by applying this methodology to the engineering TFG when possible, that is, to solve real problems related to engineering and, in addition, to add to this potentiality the fact of being precursors of innovation and developers of scientific knowledge and, if they want, to start a research career.

Ultimately, the new objectives for the Professor team of TFG of ETSEQ are that the students can learn Engineering and, at the same time, offer new knowledge and applications to Science. 


\section{References}

Bernechea, E.J., \& Arnaldos Viger, J. (2013). Design optimization of hazardous substance storage facilities to minimize project risk. Safety Science, 51, 49-62. https://doi.org/10.1016/j.ssci.2012.06.007

Cabello, A., Montané, D., Castells, F., \& Gavaldà, J. (2014, January). La integración de asignaturas al Trabajo Final de Grado en Ingeniería Química: Un paso más allá en el modelo educativo de la ETSEQ. Paper presented and published in the abstract book of II Congreso de Innovación Docente en Ingeniería Química, Escuela Técnica Superior de Ingeniería de la Universidad de Valencia, Valencia.

Caputo, A.C., Pelagaggeb, P.M., \& Palumbo, M. (2011). Economic optimization of industrial safety measures using genetic algorithms. Journal of Loss Prevention in the Process Industries, 24, 541-551. https://doi.org/10.1016/j.jp.2011.01.001

Gangopadhyay, R.K., Das, S.K., \& Mukherjee, M. (2005). Chlorine leakage from bonnet of a valve in a bullet-a case study. Journal of Loss Prevention in the Process Industries, 18, 526-530. https://doi.org/10.1016/j.jlp.2005.07.008

García, R., Font, J., \& Gavaldà, J. (2009). El Ingeniero Químico Global: Integración de conocimientos científico-técnicos y habilidades personales. Modelo educativo en la Escuela Técnica Superior de Ingeniería Química de la Universitat Rovira i Virgili. In Buenas prácticas en docencia y política universitaria (Chapter 7, pp. 135-156). Cuenca: Editions UCLM. ISBN 978-848427-645-6.

Guinea, A., Nuñez, C., \& Callau, S. (2014). TFG 214102 titled Chlorine storage unit design and application of risk mitigation measures of 173 pages. Escola Tècnica Superior d'Enginyeria Química de la Universitat Rovira i Virgili, Tarragona.

Guinea, A., Nuñez, C., Callau, S., Miñana, M., Basco, J., Gavaldà, J., et al. (2015a, June). Chlorine storage design based on risk analysis: Cost or safety? Paper presented at 7th European Meeting on Chemical Industry and Environment, Tarragona.

Guinea, A., Nuñez, C., Callau, S., Miñana, M., Basco, J., Gavaldà, J., et al. (2015b). Chlorine storage design based on risk analysis: cost or safety?. EMChIE 2015 Conference Proceedings, ISBN 978-84-8424-367-0, 1, 257-258. 
Marco, E., Peña, J.A., \& Santamaria, J. (1998). The chlorine release at Flix (Spain) on January 21st 1996: A case study. Journal of Loss Prevention in the Process Industries, 11, 153-160. https://doi.org/10.1016/S0950-4230(97)00014-4

Planas, E., Arnaldos, J., Darbra, R.M., Muñoz, M., Pastor, E., \& Vilchez, J.A. (2014) Historical evolution of process safety and major-accident hazards prevention in Spain. Contribution of the pioneer Joaquim Casal. Journal of Loss Prevention in the Process Industries, 28, 109-117. https://doi.org/10.1016/j.jp.2013.04.005

Regulation of Escola Tècnica Superior d'Enginyeria Química de la Universitat Rovira i Virgili (2014-2016).

Regulation TFG 2015-2016 and Guide of TFG of Bachelor in Chemical Engineering, Academic years 2014-2015 and 2015-2016, Tarragona.

Soman, A.R., \& Sundararaj, G. (2015). Accidental Release of Chlorine from a Storage Facility and an On-Site Emergency Mock Drill: A Case Study. The Scientific World Journal (2015), Article ID 483216, 11 pages.

Tseng, J.M., Liu, M.Y., Chang, R.H. Su, \& Shu, C.M. (2008). Emergency response plan of chlorine gas for process plants in Taiwan. Journal of Loss Prevention in the Process Industries, 21, 393-399. https://doi.org/10.1016/j.jp.2008.01.006

Vílchez, J.A., Espejo, V., \& Casal, J. (2011). Generic event trees and probabilities for the release of different types of hazardous materials. Journal of Loss Prevention in the Process Industries, 24, 281-287. https://doi.org/10.1016/j.jp.2011.01.005

\section{Published by OmniaScience (www.omniascience.com) \\ Journal of Technology and Science Education, 2017 (www.jotse.org)}

